\title{
IDENTIFICAR AS PARTES PARA TRANSFORMAR A CIDADE
}

\author{
Adilson Costa Macedo ${ }^{1}$
}

\begin{abstract}
RESUMO
Apresenta-se um conjunto de procedimentos para interpretar o tecido urbano pela natureza de suas partes, útil para a disciplina de planejamento urbano e regional e básico nas decisões para formular programas de projeto urbano. Partindo da maneira interativa de planejar e definir projetos urbanos, mostra-se como projetar a cidade com a participação dos grupos interessados. Neste sentido adotar operacionalidade simples, apoiada por programas de projeto urbano realistas onde estejam previstas medidas relacionadas à transformação da forma física e etapas de implantação, balanceadas com a participação financeira dos parceiros, as políticas públicas e gestão do projeto: proposta física e como realizá-la (implementation como procedimento indispensável). A cidade, melhor o município, se contextualiza como o todo, sendo importante considerar dois elementos principais que influem na vida urbana, o primeiro relativo aos percursos: movimento das pessoas, veículos, energia, fluídos e gás, o segundo referente aos locais de permanência: onde as pessoas convivem. Os percursos são formados por seu eixo somado a faixa lindeira de espaços livres e a faixa de terrenos ocupados ou não acompanhando o eixo, que constituem os corredores. Os espaços entre os corredores caracterizados pelas atividades de permanência são chamados de subáreas. Desta forma o espaço em estudo, independentemente de suas dimensões pode ser subdividido em corredores e subáreas. No artigo demonstra-se como a partir destes conceitos podem-se delimitar projetos urbanos, em particular configurar a classificação de tipos de centralidades desde a escala do município até a de vizinhança sendo realçada sua importância para o planejamento urbano.
\end{abstract}

PALAVRAS CHAVES: planejamento urbano, projeto urbano, gestão de projeto

\section{IDENTIFY THE SECTORS TO TRANSFORM THE CITY}

\footnotetext{
${ }^{1}$ Arquiteto, Universidade de São Paulo, FAUUSP; Master of Architecture in Urban Design, Harvard University, GSD; Doutor, Universidade de São Paulo, FAUUSP; Professor, Universidade São Judas Tadeu. E-mail: ac.macedo@terra.com.br
} 


\begin{abstract}
It presents a set of procedures to interpret the urban fabric by nature of its parts, useful for the discipline of urban and regional planning and to achieve basic decisions to formulate urban design programs. Starting from interactive way to plan and define urban projects, shows how to design the city with the participation of interested groups. In this sense adopt simple operability, backed by urban design realistic programs where they are provided for measures related to the transformation of the physical form and deployment steps, balanced with the financial participation of partners, public policy and management of the project: Physics and proposal as accomplishing it (implementation as essential procedure). The city, the municipality, if the whole being in context important to consider two key elements that influence the urban life, the first concerning routes: movement of people, vehicles, energy, fluids and gas, the second relating to places of residence: where people live. The pathways are formed by his shaft added to adjacent track of open spaces and the land occupied or not accompanying the axis, which constitute the corridors. The spaces between the corridors characterized by on-call activities are called subareas. In this way the study space, regardless of its dimensions can be subdivided into corridors and sub-areas. The article demonstrates how these concepts can delimit urban projects, in particular setting the classification of types of centers since the scale of the municipality until the neighborhood being highlighted their importance to urban planning.
\end{abstract}

KEYWORDS urban planning, urban design, design implementation

\title{
IDENTIFICAR LAS PARTES PARA TRANSFORMAR LA CIUDAD
}

\section{RESUMEN}

Presenta un conjunto de procedimientos para interpretar al tejido urbano por la naturaleza de sus partes, útiles para la disciplina de planificación urbana y regional y decisiones básicas para formular urbano diseñan de programas. A partir de manera interactiva para planificar y definir los proyectos urbanos, muestra cómo diseñar la ciudad con la participación de los grupos de interés. En este sentido adopte simple operatividad, respaldado por programas realistas diseño urbano donde se suministran para las medidas relacionadas con la transformación de los pasos de forma y despliegue físicos, equilibrado con la participación financiera de los socios, las políticas públicas y gestión del proyecto: física y propuesta como cabo (aplicación como procedimiento esencial). La ciudad, el municipio, si todo el ser en contexto importante considerar dos elementos clave que influyen en la vida urbana, la primera con respecto a las rutas: movimiento de personas, vehículos, energía, líquidos y gas, la segunda relativa a los lugares de residencia: donde vive la gente. Los caminos se caracterizan por el eje que define la pista adyacente a espacios libres y las tierras ocupadas o no acompañando al eje, llamado corredores. Los espacios entre los corredores caracterizados por actividades de guardia se denominan subáreas. De esta manera el espacio de estudio, independientemente de sus dimensiones puede ser subdividido en pasillos y zonas sub. El artículo demuestra cómo estos conceptos pueden delimitar los proyectos urbanos, en particular, establecer la clasificación de los tipos de centros desde la escala del municipio hasta el barrio que destacó su importancia para la planificación urbana.

PALABRAS CLAVE planificación urbana, diseño urbano, gestión de proyectos 
Revista Nacional de

Gerenciamento de Cidades

Como um dos instrumentos que contribuem para transformar a cidade vamos explicar procedimentos metodológicos aplicados ao projeto urbano, tendo por base a experiência resultante de trabalhos profissionais e de nossa atividade didática na universidade. Entendemos o projeto urbano no modo de urban design, à maneira norte-americana (USA-Canada), onde as transformações do tecido urbano são previstas dentro de uma área bem delimitada, onde o programa para a construção de novos espaços esteja de acordo com os interesses públicos e privados, onde os recursos financeiros sejam compatíveis com as etapas de implantação, vinculando parceiros capazes de implementar o projeto com sucesso dentro de prazo determinado. Estas condições acontecem quando o projeto urbano resulta de uma tomada de decisão ao nível do planejamento da cidade como um sistema completo, amparado no pleno aceite dos grupos sociais, econômicos e políticos interessados.

Com estas preocupações gerais em mente temos por objetivo apresentar uma maneira de conduzir o projeto urbano nos aspectos que concernem à estruturação dos espaços físicos: conceituar e mostrar como fazer o projeto das construções, de forma inserida nos itens interdisciplinares já mencionados. Construções instaladas para ser o palco dos eventos socioeconômicos e culturais que devem conferir a qualidade de vida das pessoas. São procedimentos baseados na identificação de percursos que permeiam as partes da cidade e da área objeto do projeto urbano. Os percursos de cargas e pessoas atraem atividades de importância para a cidade toda, para o bairro e para pequenas áreas de vizinhança. Desenham-se como meandros sendo alguns maiores outros menores, gerando atividades de uso diversificado nos lotes para eles voltados. Criam espaços entre eles também maiores e menores que chegam ao ponto de identificar uma pequena área de vizinhança. Vamos indicar a possibilidade de o projeto urbano chegar a proposições para melhoria dos espaços ao longo destes percursos e para o tecido urbano remanescente entre eles. A Figura 1 é um diagrama conceitual indicando 


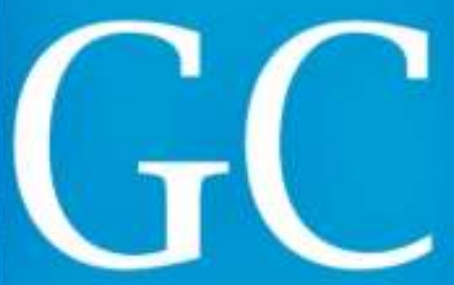

Revista Nacional de

Gerenciamento de Cidades

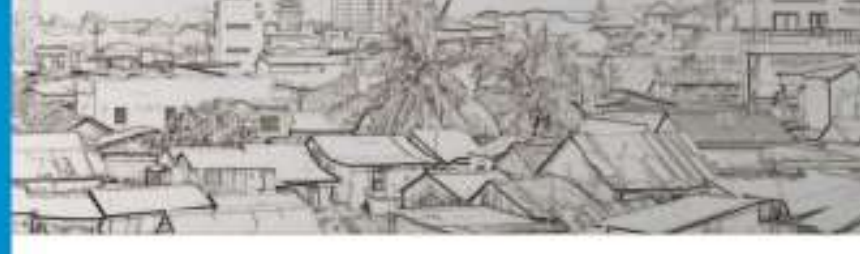

como a cidade se estrutura através dos percursos que atravessam cada bairro e das áreas maiores ou menores que surgem naturalmente entre eles. Sugere que o sistema de fluxos poderia ter uma organização boa suficientemente para se obter para cada parte da cidade uma configuração de espaços protegidos (dos veículos, com certeza!)

Figura 1. Diagrama conceitual de um bairro tradicional, ou pequena cidade.

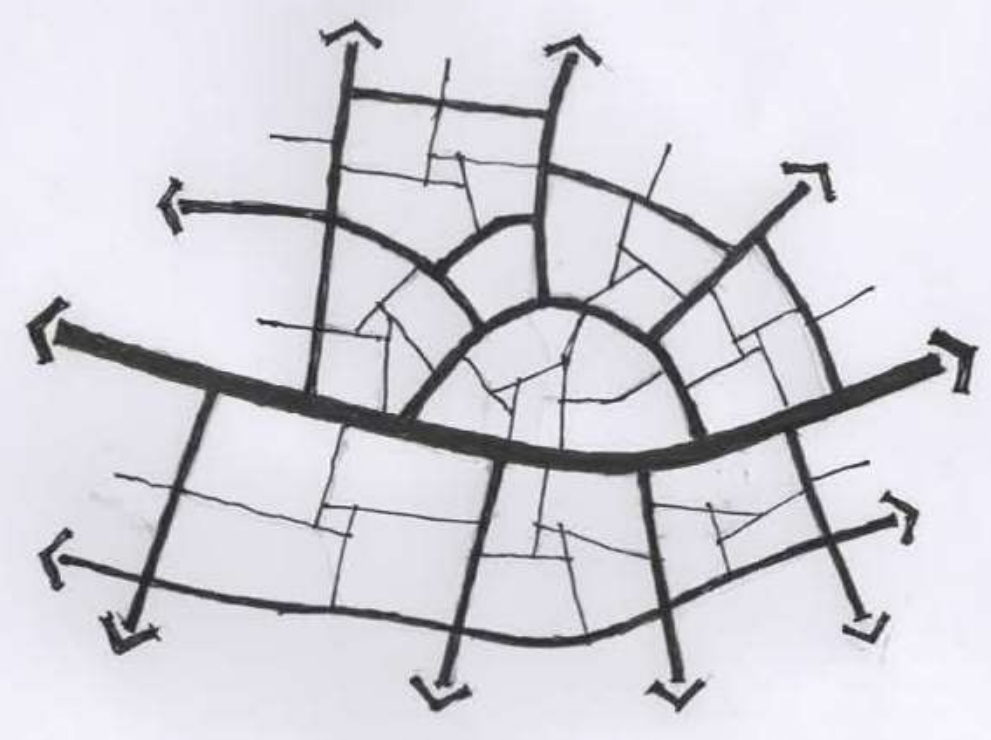

Fonte - Desenho A.C. Macedo, arquivo autor

Abrimos para discussão os procedimentos metodológicos que vimos utilizando para ser objeto de crítica e sugestões tanto na área profissional como no ensino de projeto urbano. Nossa grande pretensão é orientar o estudo interpretativo das estruturas urbanas para facilitar a maneira contemporânea de projetar com base nos locais de vizinhança das pessoas, de sua articulação com os sistemas de transportes e espaços de centralidade, agregadores de atividades em diversas escalas. O material apresentado poderá servir como contraparte a forma de atuar de colegas arquitetos e planejadores urbanos, sugerindo troca de experiências, discussão conceitual e da maneira de ensinar planejamento e projeto urbano. 
Revista Nacional de

Gerenciamento de Cidades

A discussão da natureza do projeto urbano - urban design - diferente do plano urbanístico tradicional que é sobremaneira físico traz a questão relacionada à dimensão abrangida ou seu limite físico. Tem sido realizados concursos de projetos promovidos por entidades públicas se utilizando o rótulo de projeto urbano, para nomear o plano urbanístico tradicional de uma parte, "recorte da cidade" às vezes citado, sem nenhum comprometimento financeiro para sua execução. Lembramos então da referencia aos vizinhos americanos não latinos, que entendem um plano ou projeto como algo que tenha começo, meio e fim $(\mathrm{LYNCH}, 1962)$. Sobre isto preferimos considerar o significado universal de planejamento e projeto: planejar como um processo de previsão e projetar (ou propor um plano) como um processo de fazer. Resulta do conteúdo destes conceitos que se planeja o país, a região, o município, a cidade, o bairro, a vizinhança, os espaços abertos e os edifícios. Destas várias escalas de abrangência decorrem projetos que podem ser nomeados na mesma sequencia: país, região, etc. Portanto, prever ou planejar a cidade como entidade física é organizar o percurso das pessoas, seus lugares de permanência, o percurso de cargas e infraestrutura, cobrindo toda sua superfície. Em seguida, através dos projetos de suas partes irá se buscar os objetivos almejados pelo planejamento urbano, cuja meta é obter um alto grau de qualidade de vida para a gente urbanizada e uma boa sustentação dos os espaços livres urbanos e rurais. Resulta que para uma determinada cidade os projetos urbanos, concebidos por partes, serão tantos quantos a sociedade os decidir realizar. Pensando no sentido do urbanismo sustentável, envolvendo a ideia de projetar com as possibilidades das pessoas e com a natureza, o projeto urbano pode ser entendido como projeto da cidade por suas partes, onde o todo resultará melhor que a soma das partes. Daí, como fazer a anatomia da cidade, para identificar suas partes? (ALEXANDER, 1987).

No Município de São Paulo, SP, Brasil, desde a década de 1940 tem havido uma série de planos diretores, os primeiros com ênfase na estrutura física, depois os 
Revista Nacional de

Gerenciamento de Cidades

de desenvolvimento integrado e hoje de desenvolvimento estratégico buscando a melhor maneira de dar realidade as proposições do planejamento. Os planos foram, são e certamente serão o produto do planejar como esforço para organizar o município e definir projetos urbanos. Os mais antigos decorreram da visão sobremaneira física, passando depois para o enfoque interdisciplinar do planejamento. No andar do tempo os planos foram se voltando cada vez mais para a consideração da cidade por partes, envolvendo certo grau de ausculta a população. Sem necessidade de recorrer à história do planejamento de São Paulo, destaca-se o fato do atual Plano de Desenvolvimento Estratégico, PDE se basear no princípio de considerar os percursos principais como "eixos estruturadores", e subdividir os espaços por partes grandes chamados "macro áreas" e citar partes menores referenciadas como "planos de bairro". Chegando a escala local o PDE, procura incentivar a abertura de quadras para a passagem de pedestres, apontando para estímulos aos empreendedores privados para incorporarem a recomendação em seus projetos. Daí e também pelo objetivo de São Paulo conseguir ruas com mais conforto para os pedestres, bicicletas e melhor ambientação urbana, se adotou o termo "fruição de espaços". Nestas passagens e voltadas para as calçadas das vias públicas, o planejamento prevê fachadas contínuas no térreo das edificações, com preferencia para a ocupação de uso misto, como uma releitura das fachadas com vitrines que muito nos atrai no percurso por uma rua tradicional. Com vistas à melhoria da qualidade ambiental das vias, no PDE se utilizou o termo "fachadas ativas" (PDE,2014). Em São Paulo, os planos de setores urbanos grandes por razões de serem de implantação lenta, com o passar do tempo podem ter seu perímetro modificado sem deixar de cobrir aproximadamente a mesma área. Atravessando administrações municipais diferentes, orientação política diversificada e trocas na equipe técnica de planejamento urbano os planos dos setores grandes ficam sujeitos a responsáveis técnicos com cabeças diferentes, até moldadas por conceitos internacionais mais atualizados. Um bom exemplo é o desenvolvimento dos espaços de influencia do Rio Tamanduateí. Plano urbanístico que já teve nomes 
Revista Nacional de

Gerenciamento de Cidades

como, Projeto Eixo do Tamanduateí, Operação Urbana Diagonal Sul, Operação Urbana Mooca-Vila Carioca e o atual Plano dos Bairros do Tamanduateí. A evolução da nomenclatura indica os objetivos do planejamento em cada época. Pode-se observar a abrangência da intervenção urbana passando da preocupação inicial voltada para os espaços que formam o corredor ladeando o rio (e a ferrovia que corre em paralelo), para a preocupação atual com os bairros que faceiam o rio como um todo, o que ensejou o nome do plano atual ou operação urbana consorciada. Lembramo-nos dos conceitos de fruição dos espaços e fachadas ativas encontrados no PDE para mostrar que se procura no plano para São Paulo retomar qualidades da cidade tradicional. Atitude que acompanha a tendência internacional para valorização da mobilidade individual através do transporte ciclo viário e andar a pé, em conjunto com melhorias do sistema de transporte coletivo (CALTHORPE, 1993). A menção para a ampliação da área de abrangência dos planos ao longo do Rio Tamanduateí e seu perímetro atual agora expandido abraçando os bairros limítrofes se deve ao princípio de considerar o bairro como um setor de menor escala no planejamento da cidade. Na escala do bairro seria possível haver diálogo mais próximo com a população, entender sobre suas necessidades prementes e conhecer melhor o sítio, fatores fundamentais para o desenvolvimento de um bom projeto (CAMPOS $\mathrm{F}^{\circ}$, 1989). A observação sobre São Paulo importa para a sugestão de estratégias de projeto urbano com os ingredientes de hoje, que se resumem em construir espaços para se tornarem lugares com alta qualidade ambiental e de vida urbana. Não projetamos lugares, sim espaços que poderão vir a serem lugares quando apropriados pelas pessoas. Quando se presencia um trecho da cidade que tenha um bom projeto urbano o arquiteto diz, "que espaço interessante, projeto bom", os demais cidadãos dizem "que lugar bacana". O cidadão (o arquiteto também) procura o lugar onde se sinta bem, onde haja eventos, coisas para olhar, comprar, comer, escritórios e moradias. Mesmo as áreas de predominância industrial podem ser projetadas segundo o conceito de serem lugares. O espaço projetado, resultante de programa elaborado de maneira 
Revista Nacional de

Gerenciamento de Cidades

completa traduzindo o que os interessados almejam como base de um projeto bem elaborado tem grande chance de se tornar uma construção que será chamada o lugar. Este atributo, o lugar, independe da renda dos cidadãos, pode ser lugar de pobres ou lugar de ricos. Pode ter sido proveniente da apropriação de espaços novos construídos a partir de um bom projeto urbano ou simplesmente ser um trecho da cidade existente que devido à facilidade de acesso e significado sociocultural passa a ter expressão forte como "lugar bacana" (BARNETT,2003).

Nos comentários sobre o planejamento da cidade de São Paulo destacamos a tendência dos planos chegarem a setores cada vez menores, indo até a recomendação para se estudar cada bairro. O bairro numa cidade grande é ainda uma porção grande do tecido urbano. Em São Paulo há bairros com mais de cem mil habitantes e área ocupada muito grande. Chamamos atenção para que os bairros maiores sejam formados por espaços menores de vizinhança, como o entorno de uma escola, templo, pequena área comercial, de lazer e serviços, que pode ser chamada - alguns urbanistas o fazem - de unidade de vizinhança. A área de vizinhança tem seu pequeno centro. $\mathrm{Na}$ área do bairro onde as relações de convivência são mais intensas e encontram-se equipamentos de comércio, serviços, institucionais e espaços púbicos de porte e abrangência maior, se configura o centro do bairro. Em relação à cidade inteira o centro do bairro se classifica como um subcentro. Na cidade a classificação dos espaços por área central, centro de bairro e centro de vizinhança facilita a articulação de projetos urbanos, interessantes para serem incorporados no âmbito de planejamento do município. Desta classificação se depreende uma hierarquia de espaços, interligados por um sistema de percursos. São os caminhos do transporte público, dos veículos particulares motorizados, das bicicletas e dos pedestres. Formam longas faixas que nos planos diretores dos municípios normalmente se apresentam com nomenclatura técnica adequada e bem organizada (MACEDO, 2002). Sem nada contra o planejamento oficial chamamos a atenção para uma maneira de classificar os tipos do tecido urbano de uma cidade com a pretensão de chegar ao pequeno aglomerado urbano, familiar ou aquele 


\section{Revista Nacional de}

Gerenciamento de Cidades

determinado por atividade principal, comercial, industrial, serviços ou institucional, que provoque atração diversificada para uso e ocupação do solo em seu redor. Tanto o aglomerado familiar como o gerado por outra atividade implica em percursos para sejam alcançados, sendo importante considerar nesta escala os pequenos corredores de mobilidade e as distancias para se chegar a pé até o centro Pode ser, por exemplo, a rua por onde passa o ônibus e chega numa praça, onde se encontra um templo religioso e comércio em volta. Situação que caracteriza uma centralidade no âmbito de poucas quadras que podem ser marcadas por vias de contorno para uma perfeita delimitação física da unidade de vizinhança. Como nestes lugares em geral não existe este tipo de enquadramento por vias, deve se deixar o traçado de uma diretriz para sua implantação, como uma recomendação do plano de bairro e melhor aconselhando, do plano da unidade de vizinhança. Este tipo de via de contorno candidata-se a ser o tipo mais simples de corredor da cidade marcando uma pequena subárea que é a unidade de vizinhança. Na Figura 2, procuramos mostrar usando um esquema conceitual, como os corredores fazem as ligações gerais, por onde passa o ônibus e encontram-se as atividades diversificadas. Os corredores envolvem uma área mais reservada que é a subárea, onde as ruas sejam tranquilas, possa contar com uma pequena praça pública arborizada e com alguns equipamentos de lazer para todos. 


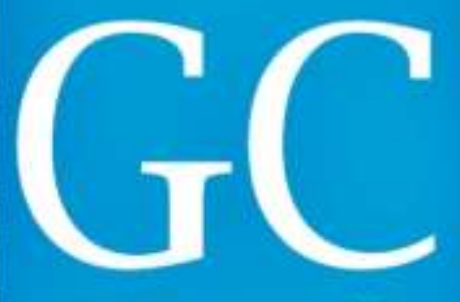

Revista Nacional de

Gerenciamento de Cidades

Figura 2 - Desenho esquemático de uma área de vizinhança.

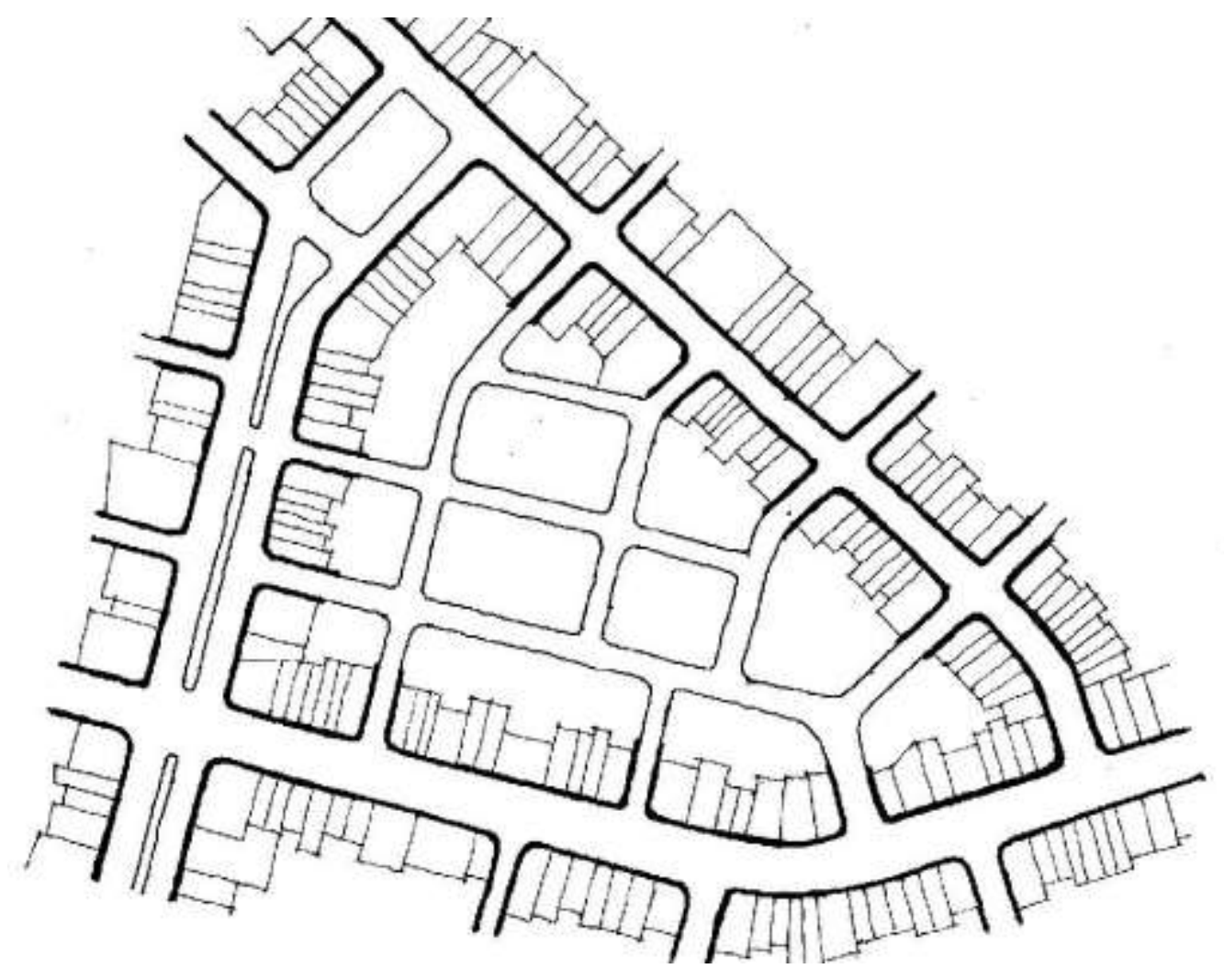

Fonte - Desenho A.C. Macedo, arquivo autor

O conceito de corredor e subárea na escala da cidade vem da apropriação do município por inteiro onde o tecido urbano consolidado permite visualizar os corredores e subáreas com maior propriedade. A definição de um corredor se faz pela soma da largura do espaço ocupado pelo percurso que o identifica, destinado a veículos sobre pneus, trilhos, água, energia ou óleo, mais a largura das vias laterais que Ihes fazem apoio, acrescido da largura dos lotes das duas faixas lindeiras. A subárea é a porção de tecido urbano que fica entre os corredores, com dimensões, volumetria das construções e aspecto sócio econômico uniforme ou não, variando 
Revista Nacional de

Gerenciamento de Cidades

conforme as distancias que separam os corredores, topografia e equipamentos de interesse público existente.

Procedimentos relacionados ao estudo dos corredores e subáreas permitem identificar as partes para transformar a cidade. Podem ser aplicados a setores do município indicados no planejamento urbano por manchas e números. Espaços onde com certeza já andaram e documentou sua visão economistas, sociólogos, geógrafos, pessoal de mercado dentre outros. Espaços que os arquitetos, pertencentes ao grupo de decisão sobre a configuração urbana, devem percorrer a pé, tirando fotos e observando padrões de uso e ocupação, também estudando mapas e o Google Earth, para traçarem proposições iniciais de perímetros para os projetos urbanos. Sendo possível fazer isto com bastante aproximação da realidade se utilizando ferramentas da simulação de dados paramétricos e do mapeamento gerado pelo SIG, Sistema de Informações Geográficas. Pela marcação e qualificação dos corredores e subáreas se faz a anatomia da cidade e se identificam projetos urbanos em diferentes escalas, ficando a decisão de desenvolver seus detalhes e proceder sua implementação para ser feita em conjunto com os grupos de interesses público e privado.

\section{REFERÊNCIAS}

ALEXANDER, C; ANNINOU, HNA; KING, I. A New Theory of Urban Design. New York. Oxford University Press, 1987.

BARNETT, J. Redesgning Cities, Principles, Practices, Implementation. Chicago, American Planning Association, 2003.

CALTHORPE, P. The Next American Metropolis. Nova York. Princeton University Press. 1993,

CAMPOS F', C M. Cidades Brasileiras: Seu Controle ou Caos. São Paulo. Editora Nobel, 1989.

LYNCH, K; Site Planning. Cambridge, MA, The MIT Press.1962

MACEDO, A C. O Espaço Urbano por Partes. Em Revista Sinopses 38 p. 11 a 16. São Paulo. Faculdade de Arquitetura e Urbanismo. Universidade de São Paulo, Outubro 2002.

PDE, PLANo de desenVolvimento estratégico, Prefeitura do Município de São Paulo, 2014. 